\title{
Aptidão e uso agrícola na área Ingarikó - Terra Indígena Raposa Serra do Sol - Roraima
}

\section{Aptitude and agricultural use in the Ingarikó area - Indian Land Raposa Serra do Sol - Roraima}

\section{Aptitud y uso agrícola en el área Ingarikó - Tierra Indígena Raposa Serra do Sol - Roraima}

http://dx.doi.org/10.21713/2358-2332.2016.v13.1038

Márcia Teixeira Falcão, doutora em Biodiversidade e Conservação pelo Museu Paraense Emílio Goeldi (MPEG) e professora da Universidade Estadual de Roraima (UERR), Boa Vista, RR, Brasil. E-mail: marciafalcao.geog@uerr.edu.br.

Sandra Kariny Saldanha de Oliveira, doutora em Biodiversidade e Conservação pelo Museu Paraense Emílio Goeldi (MPEG) e professora da Universidade Estadual de Roraima (UERR), Boa Vista, RR, Brasil. E-mail: sandrakariny@oi.com.br.

Maria de Lourdes Pinheiro Ruivo, doutora em Agronomia pela Universidade Federal de Viçosa (UFV) e pesquisadora titular do Museu Paraense Emilio Goedi (MPEG), Belém, PA, Brasil. E-mail: ruivo@museu-goeldi.br.

Lúcio Keury Almeida Galdino, doutorando em Geografia pela Universidade Federal do Ceará (UFC) e professor da Universidade Estadual de Roraima (UERR), Boa Vista, RR, Brasil. E-mail: Ikagaldino@yahoo.com.br.

\section{Resumo}

Esteartigo objetiva demonstraraaptidãoagrícolada Terra Indígena Raposa Serra do Sol (TIRSS), na região da etnia Ingarikó, em Roraima, e o 
quadro atual do uso da terra. A área de estudo se localiza no munícipio do Uiramutã, na etnorregião denominada "serras". A metodologia adotada envolveu análise de solo para determinar a granulometria, entrevistas com indígenas da etnia Ingarikó das comunidades Mapaé e Serra do Sol e elaboração de etnomapas referentes ao uso da terra pelos indígenas. Os resultados demonstram que os solos da região possuem baixa aptidão agrícola nas comunidades estudadas, com alto teor de acidez e com o predomínio de areia fina e silte. 0 uso atual da terra na região está relacionado ao plantio de roças tradicionais, caça, criação de gado e ovinos para subsistência das comunidades.

Palavras-chave: Ingarikó. Aptidão Agrícola. Roças Tradicionais.

\section{Abstract}

This article aims to demonstrate the agricultural aptitude of Indian Land Raposa Serra do Sol (TIRSS) in the region of the Ingarikó ethnicity in Roraima, and the current situation of the use of the land. The area studied is located in municipality of Uiramutã, in the etno-region called "mountain range". The methodology involved soil analysis to determine the particle size, interviews with Ingarikó Indians of the communities of Mapaé and Serra do Sol, and the development of etnomaps related to the use of the land by the Indians. The results show that the region's soil has low agricultural potential in the communities studied, high in acidity and with the predominance of fine to silty sand. The current land use in the region is related to planting of traditional plantations, hunting, and cattle and sheep breeding for the communities' subsistence.

Keywords: Ingarikó. Agricultural Potential. Traditional Fields.

\section{Resumen}

Este artículo pretende demostrar el potencial agrícola de la Tierra Indígena Raposa Serra do Sol (TIRSS), en la región de la etnia Ingarikó, en el Estado de Roraima, y la situación actual del uso de la tierra. El área 
de estudio se encuentra en municipio de Uiramutã, en la región étnica denominada "sierras". La metodología se basa en el análisis del suelo para determinar la granulometría, entrevistas con los nativos de la etnia Ingarikó de las comunidades Mapaé y Serra do Sol y la elaboración de mapas étnicos referentes al uso de la tierra por los indígenas. Los resultados muestran que los suelos de la región tienen un bajo potencial agrícola en las comunidades estudiadas, alta acidez y con el predominio de arena fina y limo. El uso actual de la tierra en la región está relacionado con la siembra de las plantaciones tradicionales, caza, creación de ganado vacuno y ovino para la subsistencia de las comunidades.

Palabras clave: Ingarikó. Aptitud Agrícola. Campos Tradicionales.

\section{INTRODUÇão}

O estado de Roraima apresenta algumas limitações em relação à aptidão agrícola, pois em geral os solos são ácidos e com alta limitação de nutrientes. A porção nordeste de Roraima, em especial a Terra Indígena Raposa Serra do Sol (TIRSS), na área denominada "etnorregião Ingarikó", localizada no município de Uiramutã, na região fronteiriça entre Brasil, República Cooperativista da Guiana e República Bolivariana da Venezuela, possui sérias limitações para o uso agrícola. A escolha da área de estudo ocorreu devido ao isolamento geográfico, pois o acesso à região ocorre apenas por via aérea, o que proporciona aos indígenas a busca pela sustentabilidade cultural e econômica.

Dessa forma, a aptidão e o uso agrícola da região possuem estreita relação com os conhecimentos dos indígenas da etnia Ingarikó sobre o ecossistema. No entanto, corroborando Melo e Schaefer (2009) e Salvador, Carvalho e Lucchesi (2011), a interferência antrópica sobre os ecossistemas produz mudanças significativas na dinâmica do solo, podendo causar mais perdas do que ganhos, com implicações em suas características físico-químicas ao longo do tempo, que devem alterar os componentes orgânicos tanto em qualidade quanto em quantidade.

A área de estudo é habitada pelos Ingarikó, pertencentes do tronco linguístico kapon e, conforme Cruz (2008), o significado de Ingarikó 
se dá pela segmentação de suas partes: inga-rï-komo > inga-rï-ko = serra, mata espessa, elemento de coesão coletivo (origem: "habitantes das serras"); outra possibilidade seria inga-rï-koto > inga-rikok > 'inga-rï-ko' = mata alta, elemento de coesão, grupo de pessoas, "povo da mata espessa, da montanha".

Os Ingarikó usam a terra de forma tradicional, por meio das roças, e em geral plantam banana e macaxeira, entre outros, além de viverem da caça e da pesca. No caso da comunidade Serra do Sol, seus habitantes criam gado de corte; já a comunidade Mapaé vive essencialmente das roças, caça e pesca.

Dessa maneira, este artigo tem como objetivo demonstrar a aptidão agrícola da TIRSS, na região da etnia Ingarikó, em Roraima, e o quadro atual do uso da terra.

\section{LOCALIZAÇÃO E CARACTERIZAÇÃO DO MEIO FísICO DA ÁREA DE ESTUDO}

A área de estudo está localizada no nordeste do estado de Roraima, no munícipio do Uiramutã, na etnorregião das serras, e constitui área de sobreposição do Parque Nacional (Parna) do Monte Roraima com a TIRSS, região de domínio da etnia Ingarikó, que envolve um total de 11 comunidades indígenas.

A pesquisa se realizou em duas comunidades Ingarikó: Mapaé e Serra do Sol, localizadas nas Folhas NB-20-Z-B e NB-20-Z-D, escala 1:250.000. A região de estudo envolve as coordenadas: N 0456'605" / W 60²8'168"; N 0507'151" / W 60³5'317"; N 0505'127" / W $60^{\circ} 23^{\prime} 004^{\prime \prime}$ (Figura 1). 
Figura 1 - Localização da área de pesquisa

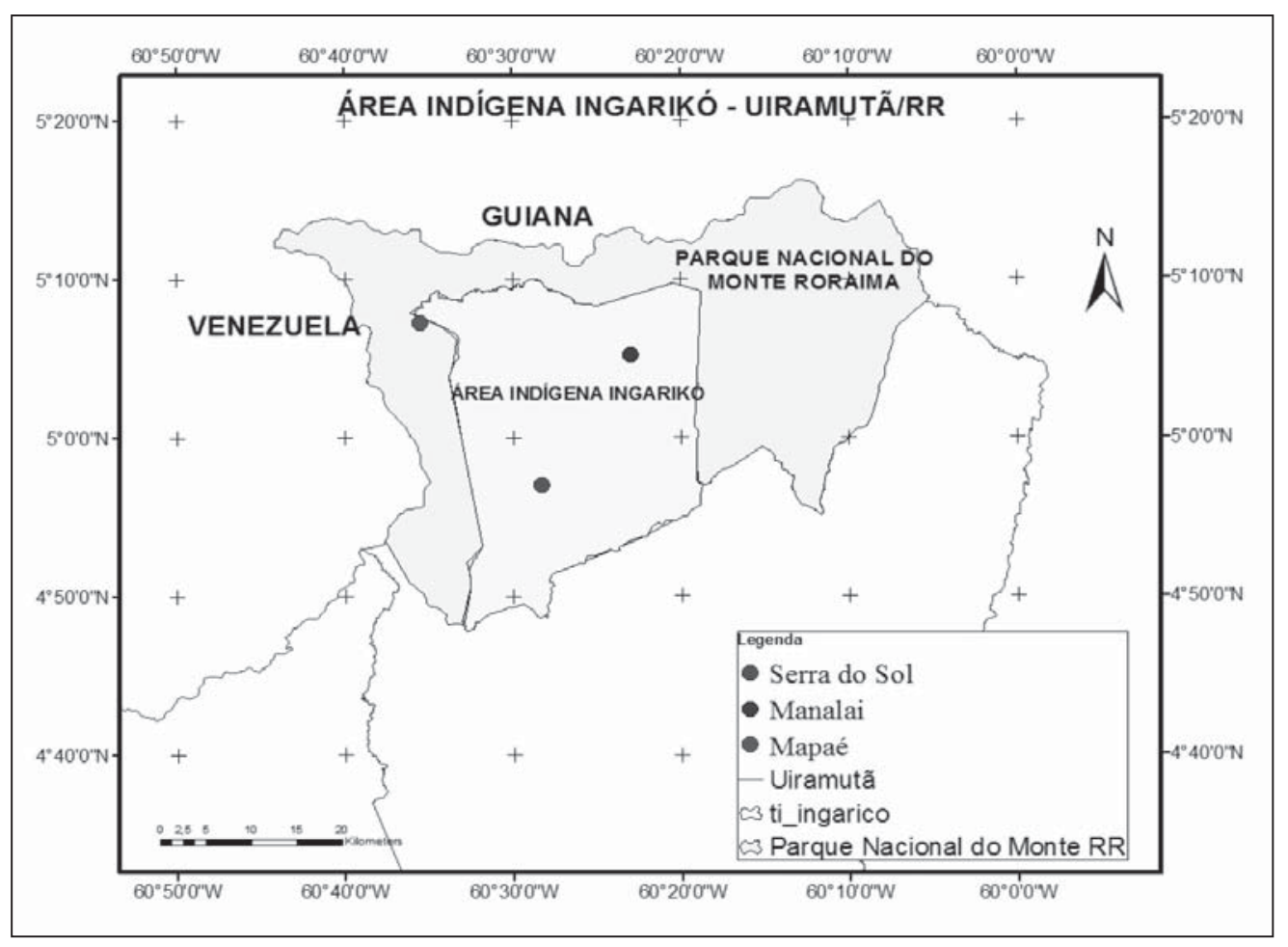

Fonte: Falcão (2016).

\section{FISIOGRAFIA DA ÁREA}

Conforme Falcão e Costa (2014), Roraima congrega tipologias climáticas diferenciadas devido à disposição física do estado, ladeado ao sul e oeste pela Floresta Amazônica, a leste pelas savanas que se estendem pelos campos da Guiana, e ao norte pelo complexo montanhoso Roraima/Pacaraima, que condiciona três aspectos climáticos diferenciados, conforme a classificação de Köppen: $A f$, Aw e $A m^{1}$.

O clima da área estudada, segundo a classificação de Köppen, caracteriza-se por ser do tipo Aw, com médias pluviométricas em torno de $1.750 \mathrm{~mm}$ anuais, com chuvas concentradas entre os meses de maio e agosto, e períodos de baixos índices entre os meses de setembro e abril; e $A m$ (chuvas do tipo monção), que se caracteriza por ser intermediário entre o $A w$ (verão úmido e inverno seco) e $A f$ (úmido), estabelecido por um corredor florestal influenciado pela savana e pelo relevo (BARBOSA, 1997).

Classificação climática de Wilhelm Köppen, que considera a temperatura e a precipitação, compreendendo um conjunto de letras maiúsculas e minúsculas para designar os grupos climáticos (MENDONÇA; DANNI-OLIVEIRA, 2007). 
A vegetação, conforme descrito por Schaefer et al. (2005) e Schaefer e Vale Júnior (1997), configura-se pela presença da floresta de montana aberta, sobreposta aos solos do tipo neossolos litólicos e cambissolos, na comunidade de Mapaé (Figura 2), já na comunidade Serra do Sol, predominam ainda os campos rupestres altimontanos sobrepostos aos neossolos e cambissolos distróficos (Figura 3), que se caracterizam pela presença de um tapete graminoso ralo com o domínio de algumas espécies como o Trachypogon sp (capim-ponta-de-lança).

Figura 2 - (a) Floresta de montana aberta, vista aérea do entorno da comunidade Manalai; (b) Perfil esquemático da floresta de montana, baseado em Veloso (1975)
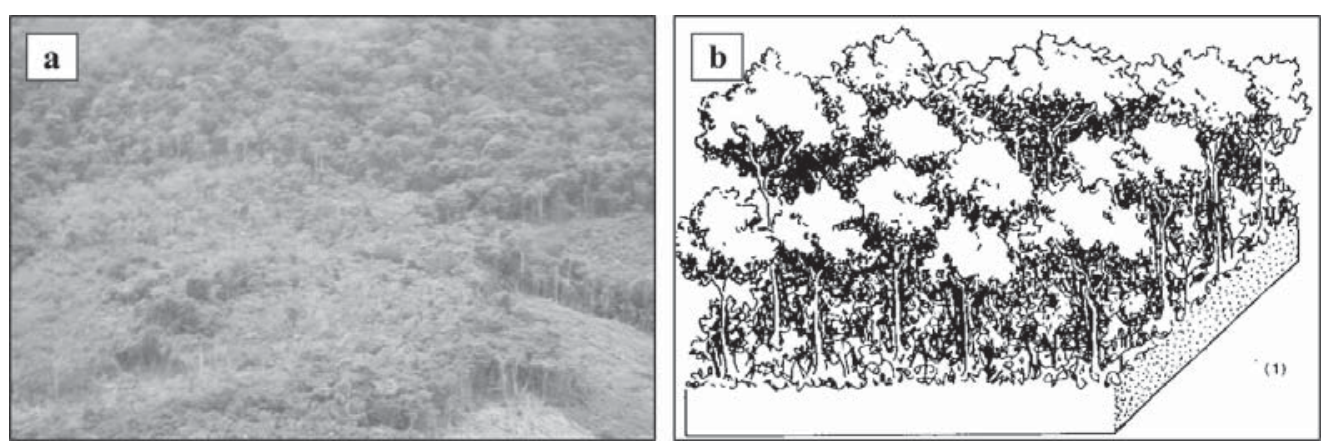

Fonte: Falcão (2016), modificado de Veloso (1975).

Figura 3 - (a) Campos rupestres, vista parcial da comunidade indígena Serra do Sol; (b) Perfil esquemático dos campos rupestres
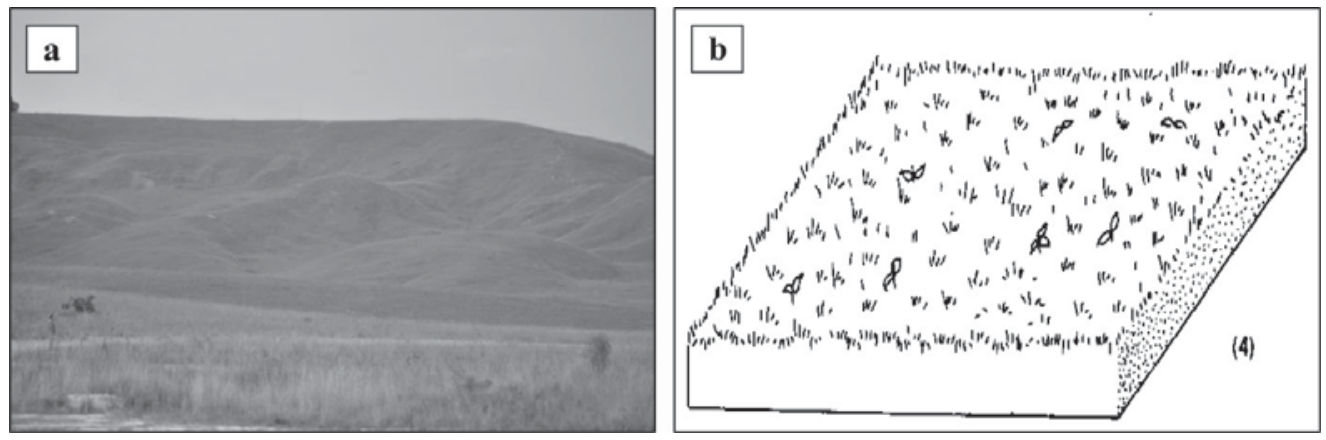

Fonte: Falcão (2016), modificado de Veloso (1975).

A geologia da área em estudo pertence ao domínio do "Supergrupo Roraima". Pinheiro, Reis e Costi (1990) e Costa e Fernandes (2012) em seus estudos relacionaram o desenvolvimento geológico dessa região a um evento distensional com direção geral $\mathrm{N}-\mathrm{S}$, responsável pelo desenvolvimento de falhas normais E-W e de transferência. 
A região caracteriza pela presença de grandes mesas chamadas regionalmente pelos indígenas de tepuys com topos em geral aplainados que se destacam de forma isolada, a exemplo do Monte Roraima, que possui uma pequena área no território brasileiro (apenas 5\%).

A geomorfologia é marcada pela presença de escarpas erosivas, que em geral são côncavas e intensamente ravinadas, com formação de depósito de tálus, semelhante a estrutura geológica. Nota-se a presença dos vales encaixados, os quais proporcionam o acomodamento da drenagem, a exemplo o rio Cotingo.

Destaca-se ainda a presença de cristas assimétricas, denominadas de hogbacks. O relevo da região é propício à intensa morfogênese (erosão e ravinamento). Na região, nota-se ainda a presença de falhas transcorrentes. As falhas normais expressam no relevo mediante escarpas de falha e facetas trapezoidais que, por sua vez, controlam a orientação geral das serras. Estas alcançam altitudes de mil metros no sistema Pacaraima.

\section{MATERIAL E MÉTODOS}

\subsection{Procedimentos e coleta de dados}

A coleta de dados ocorreu mediante solicitação de autorizações junto às comunidades envolvidas por meio do líder (tuxaua) de cada comunidade. Ele indicou os dez participantes, sendo seis agricultores da Serra do Sol e quatro agricultores de Mapaé, que lidam diretamente com os locais a serem utilizados para as roças.

Antes de cada entrevista, apresentou-se aos informantes um Termo de Consentimento Livre e Esclarecido (TCLE) e um termo de autorização para o uso de imagem para se manifestarem acerca de sua participação da pesquisa, segundo as normas estabelecidas pela Resolução n 196, de 10 de outubro de 1996, do Conselho Nacional de Saúde, e aprovadas pelo Comitê de Ética em Pesquisa da Universidade Federal de Roraima ( $n^{\circ}$ 758.921), pelo Comitê Nacional de Ética e Pesquisa (n CAAE 19903813.1.0000.5302), pelo Instituto Nacional do 
Patrimônio Histórico Cultural (n²4/2014), pelo Instituto Chico Mendes da Biodiversidade-ICMBio/SISBIO (n³6346) e pela Fundação Nacional do Índio Funai (n²8/AAEP/PRES/2025), . As assinaturas dos termos foram obtidas individualmente, depois de serem explicados verbalmente os objetivos e a metodologia que seria utilizada na pesquisa.

Durante a pesquisa, foi realizado acompanhamento com informantes-chave no preparo das roças, a fim de observar os locais de cultivo, formas de preparo e manejo do solo. Efetuou-se coleta de coordenadas geográficas, registros fotográficos e anotações em caderneta. Com trado holandês, coletaram-se cerca de 1,5k de amostras de solo em cinco pontos estratégicos de cada comunidade (Mapaé e Serra do Sol) para análise em laboratório. As amostras foram reunidas em um balde plástico limpo, bem misturadas, formando uma matéria composta. Depois da homogeneização, retiraram-se, aproximadamente, $500 \mathrm{~g}$ de solo, que foram transferidos para saco plástico sem uso. As amostras foram identificadas pelo número correspondente da área, especificando-se informações complementares, como as coordenadas da região.

O trabalho em laboratório envolveu a preparação das amostras para classificação granulométrica: $100 \mathrm{~g}$ de solo foram destorroados em gral de porcelana, acrescentados de $400 \mathrm{ml}$ de $\mathrm{H}_{2} \mathrm{O}$ e levados para a lavadora ultrassônica Unique. O material diluído foi secado à temperatura ambiente e então peneirado em malha de $2 \mathrm{~mm}$ para obter a terra fina seca. Em seguida, foi realizada a separação das frações de argila, silte e areia: mediante o peneiramento, obteve-se a fração de argila e, por via úmida, as frações de silte e argila (EMBRAPA, 2006). Posteriormente, os dados obtidos foram tratados no software SysGran na versão 3.0.

\section{APTIDÃO AGRÍCOLA DA REGIÃO ESTUDADA}

A região Ingarikó está inserida em uma área que se constitui de manchas de florestas de montanhas sobrepostas aos argissolos, diabásio - na qual existem possibilidades de cultivos de subsistência e campos rupestres com potencialidade agrícola ainda muito limitada. 
Logo, os solos da região se caracterizam pelo alto teor de acidez, com teor de argila acima de 30\%. Esses solos estão posicionados em áreas de relevo ondulado, dissecado e com erosão laminar, e, principalmente na comunidade Serra do Sol, com déficit hídrico prolongado (média de seis meses), presença de matacões rochosos e baixos teores de fósforo.

Conforme o Quadro 1, as propriedades químicas dos solos das comunidades Mapaé e Serra do Sol se configuram por terem alto teor de acidez ( $\mathrm{pH}$ entre 3,9 e 4,9) e baixos teores de $\mathrm{Ca}^{+}, \mathrm{Mg}^{2+}, \mathrm{K}^{+}$e $\mathrm{Al}^{3+}$.

Quadro 1 - Características químicas dos solos da região Ingarikó

\begin{tabular}{|c|c|c|}
\hline \multirow{2}{*}{ Característica química do solo } & \multicolumn{2}{|c|}{ Comunidades Ingarikó } \\
\cline { 2 - 3 } & Mapaé & Serra do Sol \\
\hline $\mathrm{pH}$ & 4,9 & 3,9 \\
\hline $\mathrm{Ca}^{2+}$ & 0,33 & 0,11 \\
\hline $\mathrm{Mg}^{2+}$ & 0,28 & 0,06 \\
\hline $\mathrm{K}^{+}$ & 0,06 & 0,08 \\
\hline $\mathrm{Al}^{3+}$ & 0,78 & 0,73 \\
\hline
\end{tabular}

Fonte: Falcão(2016)

Hernandez e Silveira (1998) verificaram baixos teores de magnésio no solo, resultando em diminuição na produção das plantas. A relação cálcio e alumínio pode ser usada como indicador dos processos que contribuem para a acidificação do solo.

Com base nas análises granulométricas, os solos da região estudada se caracterizaram por terem alto teor de areia e arenito, decorrentes do intemperismo das rochas sedimentares areníticas. $\mathrm{Na}$ comunidade Mapaé, a fração de areia variou entre 0,5 e 2,5, ou seja, areia fina; na Serra do Sol, entre 2,5 e 4,0, isto é, presença de areia fina e silte (Figura 4). 
Figura 4 - (a) Distribuição granulométrica da comunidade Mapaé; (b) Distribuição granulométrica da comunidade Serra do Sol
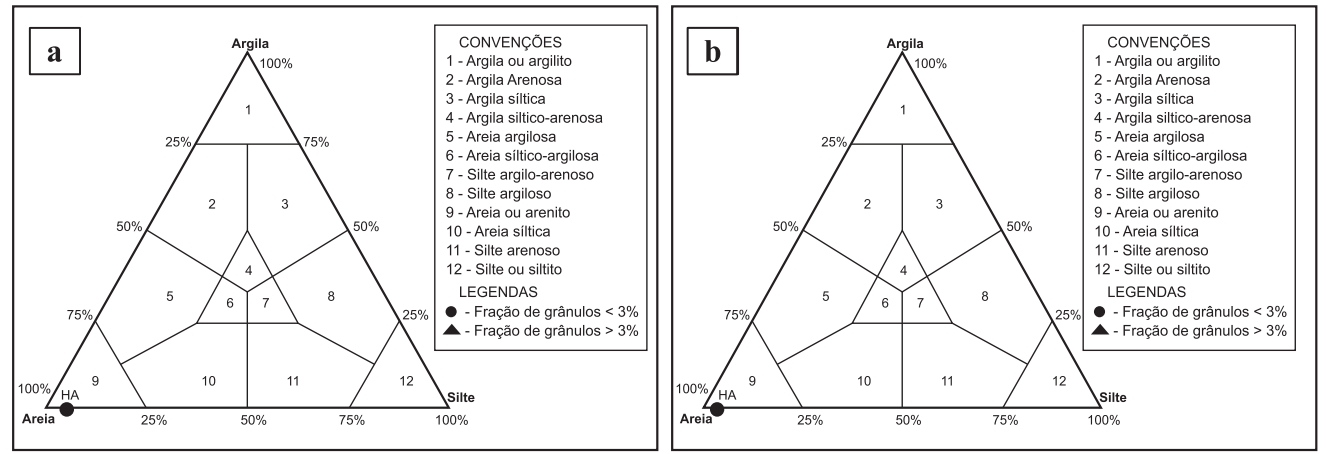

Fonte: Falcão ( 2016).

Os dados corroboram Costa e Beserra Neta (2011), pois, em trabalhos realizados na Serra do Tepequém, os autores sugerem que o intemperismo de rochas sedimentares proporciona o transporte dos grãos a curta distância, talvez por movimentos de massas, escorregamento ou fluídos de alta densidade. Na região da TIRSS, percebe-se a mesma situação, no entanto, com a presença de uma vegetação mais rala (campos rupestres), o processo de dissecação (trabalho erosivo) é mais evidente.

Conforme relatos dos Ingarikó e os resultados das análises, os solos da região possuem sérias limitações para o uso agrícola. Alguns relataram que o processo de queima periódica, com o passar dos anos, proporciona a exaustão do solo.

Para Haverroth (2010), com a queima da floresta, a biomassa se transforma em cinza, que serve de "fertilizante" e neutraliza a acidez do solo. Porém, depois de alguns anos de cultivo, essa fertilidade diminui, levando ao abandono dessas áreas e promovendo a abertura da floresta a outros plantios.

\section{USO ATUAL DA TERRA PELOS INGARIKÓ}

Com base nas pesquisas in loco e nas entrevistas com os Ingarikó, o uso atual da terra na região está relacionado ao plantio de roças (umé) tradicionais, caça, criação de gado e ovinos para subsistência do povo. 
Cardoso (2010) enfatiza a constituição da roça como o espaço de excelência na agricultura da região Amazônica. Trata-se de um espaço nascido de um "distúrbio" mediante corte e queima da floresta, objetivando segurança alimentar de uma família, de uma comunidade local ou de uma região e, em muitos casos, servindo como complemento da renda familiar e troca com vizinhos e parentes.

Com relação às roças tradicionais, o processo de escolhas das novas roças ocorre durante o período seco (toronkan) quando os Ingarikó fazem a broca, derrubada e a queima, já no período chuvoso (tîmon) ocorre o plantio, e os indígenas buscam alternativas tais como: a caça e a pesca, conforme o calendário agrícola "celestial" dos Ingarikó, que orienta a agricultura (Figura 5).

\section{Figura 5 - Calendário agrícola Ingarikó}

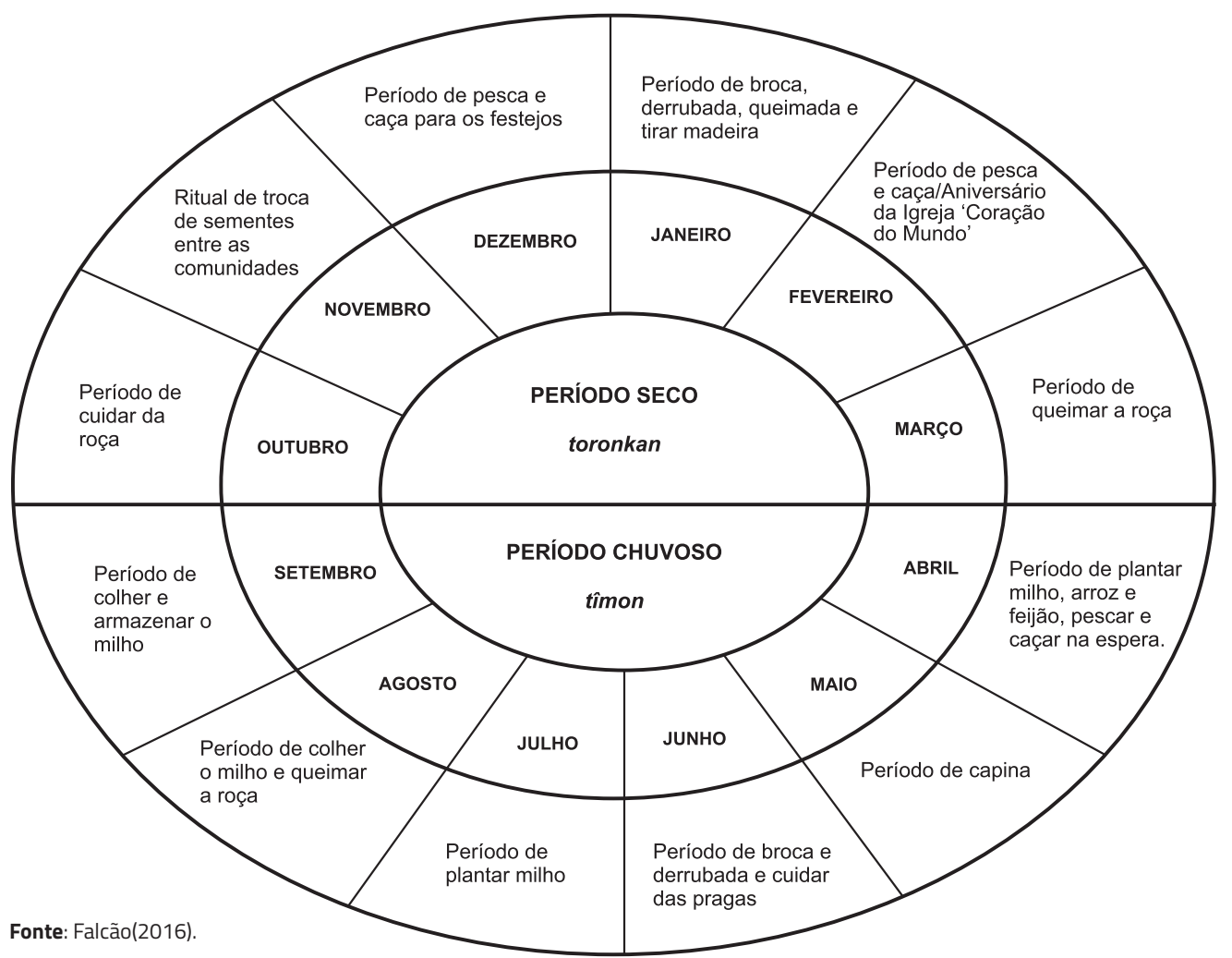

As roças dos Ingarikó se localizam, em geral, nas encostas do relevo. 0 uso da área, segundo os agricultores, dura em média um ano. Conforme informações obtidas, o período de pousio das roças dura em média de três a quatro anos. Diante dessa questão, atualmente, as roças 
se localizam cada vez mais distantes - em média um dia de caminhada da comunidade.

No entanto, nota-se em alguns casos, como na Serra do Sol, que o tempo de plantio das roças não está respeitando o período de pousio, proporcionando intensa erosão e ravinamento no solo. Clement et al. (2010) ressaltam que o período de pousio curto interfere no processo de sucessão secundária, consequentemente, na manutenção da diversidade genética e biológica em forma de banco de sementes.

Com relação aos tipos de solos, os Ingarikó associam as unidades geomorfológicas a sua utilização: nas serras em geral, são encontrados os solos escuros (marrom e preto), propícios para o cultivo de maniva, banana e feijão. Já os solos lavrados, em geral, são de coloração alaranjada e servem para o plantio de mandioca e abóbora. Os solos escuros são encontrados na área de vazante, devido à proximidade com a rede hídrica, e servem para o cultivo de mandioca e maniva (Quadro 2).

\section{Quadro 2- Descrição do tipo de solo e uso da terra pelos Ingarikó}

\begin{tabular}{|l|l|l|}
\hline \multicolumn{1}{|c|}{$\begin{array}{c}\text { Unidades } \\
\text { geomorfológicas }\end{array}$} & \multicolumn{1}{c|}{ Tipo de solo } & \multicolumn{1}{c|}{ Uso } \\
\hline Serras & $\begin{array}{l}\text { Marrom (tapinuknan) e } \\
\text { Preto (Ikkîrîn) }\end{array}$ & $\begin{array}{l}\text { Roça: plantio de maniva, } \\
\text { banana, feijão. }\end{array}$ \\
\hline Lavrado & $\begin{array}{l}\text { Alaranjado } \\
\text { (Karakuwapan) }\end{array}$ & $\begin{array}{l}\text { Roça: plantio de } \\
\text { mandioca e abóbora. }\end{array}$ \\
\hline Vazante & Preto (Ikkîrîn) & $\begin{array}{l}\text { Roça: Plantio de } \\
\text { mandioca e abóbora. }\end{array}$ \\
\hline
\end{tabular}

Fonte: Falcão ( 2016).

Os Ingarikó diferenciam os solos como "bom" (férteis), que possuem coloração escura e, os "ruins" (não férteis), em geral solos claros e pedregosos. Segundo o Sr. Arlindo Luiz, um dos entrevistados, "A comunidade reconhece olhando, quando retira a planta, se a raiz for profunda, a terra é boa, se não for, a terra é ruim". (comunicação verbal).

O conhecimento sobre o solo torna-se de extrema importância para a plantação das roças (umè). Os indígenas ressaltaram ainda outros 
padrões de reconhecimento do solo tais como: cor, tipo de planta e cheiro. No que se refere ao significado de solo o Sr. Gelson Martins, um dos entrevistados, mencionou que o solo significa terra, que se configura como "o espaço onde se planta" (comunicação verbal).

Dentre os principais cultivos nas roças, principalmente nas comunidades Manalai e Mapaé e na Serra do Sol, encontram-se em maior quantidade o plantio de mandioca braba, pimenta canaimé (utilizada também no ritual de iniciação do menino, no qual é inserido o sumo da pimenta nos olhos do jovem iniciante) e milho. Os principais produtos estão descritos no Quadro 3.

Quadro 3 - Principais produtos cultivados nas roças Ingarikó

\begin{tabular}{|c|c|c|c|}
\hline Nome científico & Nome vulgar & Nome Ingarikó & Armazenagem \\
\hline $\begin{array}{l}\text { Solanum } \\
\text { tuberosum }\end{array}$ & Batata & Sak & $\begin{array}{c}\text { Não é } \\
\text { armazenada }\end{array}$ \\
\hline Dioscorea spp & Cará & Napii & $\begin{array}{c}\text { Não é } \\
\text { armazenada }\end{array}$ \\
\hline $\begin{array}{c}\text { Ananas comosus } \\
\text { (L.) Merril }\end{array}$ & Abacaxi & Kaiwarak & $\begin{array}{c}\text { Não é } \\
\text { armazenada }\end{array}$ \\
\hline Capsicum chinense & Pimenta Canaimé & Pimii & $\begin{array}{c}\text { Armazenam em } \\
\text { forma de molho, } \\
\text { ou em pó seco a } \\
\text { fogo }\end{array}$ \\
\hline Manihot esculenta & Mandioca & Nak & $\begin{array}{c}\text { Não é } \\
\text { armazenada }\end{array}$ \\
\hline Zea mays & Milho & Aknaik & \begin{tabular}{|c|} 
Armazenam \\
os grãos em \\
garrafas, sacos \\
ou penduram na \\
direção da fumaça
\end{tabular} \\
\hline Musa spp & Banana & Pananayek & $\begin{array}{c}\text { Não é } \\
\text { armazenada }\end{array}$ \\
\hline $\begin{array}{l}\text { Saccharum } \\
\text { officinarum }\end{array}$ & Cana-de-açúcar & Siikaru & $\begin{array}{c}\text { Não é } \\
\text { armazenada }\end{array}$ \\
\hline
\end{tabular}

Fonte: Falcão (2016).

A base da alimentação dos entrevistados é a mandioca braba, a partir desta se produz o beiju (serve como acompanhamento em todas as refeições), o caxiri e o pajuaru (bebidas típicas à base de mandioca). 
A produção desses alimentos é realizada pelas mulheres. Elas vão até a roça para coletar o produto, depois retiram a casca, lavam e ralam a mandioca. Para a produção do caxiri, a mandioca ralada é cozida por mais de duas horas, depois é acrescentada a batata roxa para dar a coloração avermelhada; depois de esfriar, o produto pode ser consumido, para ficar alcoólico, é armazenado em baldes plásticos por vários dias.

O beiju é produzido a partir da prensa da massa no tipiti (instrumento indígena feito de palha de arumã, que remove todo líquido da massa da mandioca). Depois de todo o líquido ser retirado, a massa seca vai ao fogo em uma espécie de forma, é assada e vai ao sol para ficar bem seca.

Ressalta-se que o ambiente natural da região Ingarikó, em sua maioria, ocasiona limitação à sobrevivência da etnia, motivando diversas situações, como a presença de uma forma bem evidente dos programas governamentais como: Vale Família e Vale Solidário.

Outro fator importante é a união do povo Ingarikó, o qual busca, por meio de projetos, o resgate das sementes tradicionais, bem como a implantação de programas, dos quais, atualmente, vem se destacando a Unidade Demonstrativa² Nutrir.

O Nutrir surgiu da iniciativa dos Ingarikó em parceria com a Fundação Nacional do Índio, Instituto Federal de Educação, Ciência e Tecnologia de Roraima, Conselho do Povo Indígena Ingarikó e o Instituto Socioambiental de Roraima. Entre os objetivos do projeto está a prática de atividades de agroecologia, com foco na produção animal e vegetal, visando à segurança alimentar e à melhoria da qualidade de vida dos Ingarikó.

\section{CONSIDERAÇÕES FINAIS}

2 Termo utilizado pelos ingarikó para se referir ao projeto NUTRIR
Os solos da região Ingarikó se caracterizam por apresentar baixa fertilidade natural, logo esse é um dos fatores que induz a uma constante mudança de área de plantio (roça), visto que o sistema de manejo das 
culturas ocorre por meio de queima. Esse processo proporciona o incremento temporário da fertilidade, em função das cinzas, no entanto, concentra-se nas camadas superficiais, o que permite a exploração das áreas por um período máximo de quatro anos.

Dessa forma, a problemática da restrição nos solos da região promove, atualmente, o cultivo cada vez mais distante das comunidades estudadas - em média um a dois dias de caminhada. As roças próximas estão localizadas em área de vertente do relevo, portanto intensificando os processos erosivos, pois o tempo de pousio é curto e o solo de baixa fertilidade, consequentemente a exaustão desse solo vem se tornando frequente na região, principalmente, nas comunidades Serra do Sol e Manalai. Todavia, na comunidade Mapaé, nota-se maior diversidade de cultivos, e o solo apresenta melhor fertilidade.

Assim, novos estudos agrícolas, em especial pedológicos, podem contribuir para melhorar a produtividade, mediante implantação de projetos - como o projeto Nutrir, hoje em andamento - e cursos de capacitações para agregar novos conhecimentos à cultura alimentar do povo, visto que atualmente a região é acometida por problemas nutricionais. Segundo os Ingarikó, eles buscam conhecimentos do "não índio" para que possam usar e manejar a terra de maneira correta, sendo, portanto, abertos a novos saberes e pesquisas em sua região.

\section{Referências}

BARBOSA, R. I. Distribuição das chuvas em Roraima. In: BARBOSA R. I.; FERREIRA, E. J. G.; CASTELLÓN, E. G. (Eds.). Homem, ambiente e ecologia no estado de Roraima. Manaus: INPA, 1997. p. 325-335.

CARDOSO, T. M. 0 saber biodiverso: práticas e conhecimentos na agricultura indígena do baixo rio Negro. 1 ed. Manaus: Edua, 2010.

CLEMENT, C. P. et al. Diversidade vegetal em solos antrópicos da Amazônia. In: TEIXEIRA, W. G. et al. (Eds.). As terras pretas de índio da Amazônia: sua caracterização e uso deste conhecimento na criação de novas áreas. Manaus: Edua, 2010. p. 147-162. 
COSTA, J. A.; FERNANDES, M. L. Monte Roraima e Pico da Neblina: pontos culminantes do Brasil. In: HASUI, Y. et al. (Orgs.). Geologia do Brasil. São Paulo: Beca, 2012. p. 190-199.

COSTA, M. L. C.; BESERRA NETA, L. C. Textura e mineralogia de solos na serra do Tepequém: diversidade e litodependência. In: NASCIMENTO, R. S. C.; HORBE, A. M. C.; ALMEIDA, C. M. (Orgs.). Contribuições à Geologia da Amazônia. Belém: SGBG, 2011. p. 57-79. v. 7.

CRUZ, O. Os Ingarikó (Kapon) na Terra Indígena Raposa Serra do Sol. Tensões Mundiais, Fortaleza, v. 4, n. 6, p. 117-154, 2008.

EMBRAPA. Centro Nacional de Pesquisa de Solos. Sistema brasileiro de classificação de solos. 2. ed. Rio de Janeiro: Embrapa, 2006.

FALCÃO, M.T. Ambiente e conhecimento tradicional da etnia Ingarikó na terra indígena Raposa Serra do Sol - Roraima: abordagem etnocientífica no estudo do uso da terra. 2016. 105f. Tese. (Doutorado em Biodiversidade e Conservação) - Museu Paraense Emilio Goeldi Belém - PA, 2016.

FALCÃO, M. T.; COSTA, J. A. V. Paisagem geomorfológica da terra indígena Raposa Serra do Sol - Uiramutã/Roraima/Brasil. Revista Geonorte, Manaus v. 10, n. 5, p. 71-75, 2014. Edição Especial 4. Disponível em: <http:// www.periodicos.ufam.edu.br/revista-geonorte/article/view/1442/1327>. Acesso em: 2 nov. 2016.

HAVERROTH, M. Agricultura indígena e princípios agroflorestais. In: SILVA, V. A.; ALMEIDA, A. L. S.; ALBUQUERQUE, U. P. (Orgs.). Etnobiologia e Etnoecologia: pessoas \& natureza na América Latina. Recife: NUPEEA, 2010. p. 307-320.

HERNANDEZ, R. J.; SILVEIRA, R. I. Efeitos da saturação por bases, relações Ca:Mg no solo e níveis de fósforo sobre a produção de material seco e nutrição mineral do milho (Zea mays L.). Scientia Agricola, Piracicaba, v. 55, n. 1, p. 79-85, 1998. Disponível em: <http://www.scielo.br/scielo. php?script=sci_arttext\&pid=S0103-90161998000100014>. Acesso em: 2 nov. 2016. 
MELO, V. F.; SCHAEFER, C. E. G. R. Matéria orgânica em solos desenvolvidos de rochas máficas no nordeste de Roraima. Acta Amazônica, Manaus, 2009, v. 39, n. 1, p. 53-60, 2009. Disponivel em: <http://dx.doi.org/10.1590/ S0044-59672009000100005>. Acesso em: 2 maio 2013.

MENDONÇA, F.; DANNI-OLIVEIRA, I. M. Climatologia: noções básicas e climas do Brasil. 1 ed. São Paulo: Oficina de Textos, 2007.

PINHEIRO, S. S.; REIS, N. J.; COSTI, H. T. Geologia da região de Caburai, Nordeste de Roraima. Texto explicativo. Brasília, DF: CPRM, 1 ed. 1990.

SALVADOR, J. T.; CARVALHO, T. C.; LUCCHESI, L. A. C. Relações cálcio e magnésio presentes no solo e teores foliares de macronutrientes. Revista Acadêmica: Ciência Animal, Curitiba, v. 9, n. 1, p. 27-32, 2011.

SCHAEFER, C. E. R.; VALE JÚNIOR, J. F. Mudanças climáticas e evolução da paisagem em Roraima: uma resenha do Cretácio ao Recente. In: BARBOSA R. I.; FERREIRA, E. J. G.; CASTELLÓN, E. G. (Eds.). Homem, ambiente e ecologia no estado de Roraima. Manaus: INPA, 1997.

SCHAEFER, C. E. R. et al. Diagnóstico ambiental e sustentabilidade da área indígena Raposa Serra do Sol. Revista Ação Ambiental, Viçosa, v. 8, n. 32, p. 31-38. 2005.

VELOSO, H. P. et al. Projeto Radambrasil: levantamento dos recursos naturais. Folha NA 20 Boa Vista e parte das Folhas NA 21 Tumucumaque, NB 20 Roraima e NB 21. Rio de Janeiro: DNPM, 1975.

Recebido em 01/05/2016

Aprovado em 03/10/2016 